\title{
Rheological Behavior and Organoleptic Effects of Ovalbumin Addition in Yogurt Mousse Production
}

\author{
M. Menéndez, ${ }^{*}$ B. Paredes, ${ }^{\star}$ O. Iglesias, ${ }^{\star}$ M. Rendueles, $†$ and M. Díaz ${ }^{\star 1}$ \\ ${ }^{*}$ Chemical Engineering and Environmental Technology Department, University of Oviedo, C/Julián Clavería 8, 33006 Oviedo, Spain \\ †Project Management Area, University of Oviedo, C/Independencia, 1333004 Oviedo, Spain
}

\begin{abstract}
Yogurt mousse is a novel, high added-value dairy product that has been well received by the market. This paper presents a study of the effect of the addition of ovalbumin to the product on its rheological and organoleptic qualities. The ovalbumin was previously separated from egg white with a high grade of purity using an ion exchange resin synthesized by the authors. Diverse rheological tests at different temperatures and corresponding sensorial assessments were conducted to compare samples without and with added ovalbumin.

The obtained results confirm that the product is viscoelastic and combines the properties of foams and emulsions; the elastic component is greater than the viscous component. Moreover, at temperatures ranging from 5 to $15^{\circ} \mathrm{C}$, a usual interval of consumption, the product behaves rheologically in a similar way. Conversely, the addition of ovalbumin under the assayed conditions also makes the elastic character of the product increase at a given temperature. Finally, the sensorial assessment tests and determinations of stability and volume yield enabled us to verify that the addition of ovalbumin at an amount of $1.3 \%$ hardly alters the stability, resistance to shear stress, or the texture and improves the degree of foaming. Therefore, the product with additive is of good commercial quality.
\end{abstract}

Key words: mousse, yogurt, ovalbumin, rheology

\section{INTRODUCTION}

One of the most useful tools for studying the texture of products, both in cosmetics and in pharmaceutical and food products, is rheology (Steffe, 1996; Guerrero et al., 1998; Gallegos and Franco, 1999; Langevin, 2000). Rheology and the study of elastic and viscous behaviors are also used to investigate more complex systems, which in turn present intermediate properties by virtue of their composition and structure (i.e., they are visco-

Received July 26, 2005.

Accepted October 18, 2005.

${ }^{1}$ Corresponding author: mariodiaz@uniovi.es elastic substances). Within this group, dairy gels are included (Everett and Olson, 2000; Koh et al., 2002).

The dairy industry is continuously developing novel products, especially fermented desserts, of a more or less sophisticated texture and with great added value. The flow properties of these new products, among their other properties, are being studied (Pintado et al., 1998; Abu-Jdayi and Mohameed, 2002). A recent example has been the introduction on the European market of yogurt mousse. Yogurt mousse is an interesting viscoelastic product that combines the properties of emulsions and foams (Paredes et al., 2004); its commercial success is based on these qualities, which are fundamentally related to its appearance and texture. Rheometry is the most valuable tool for studying the properties of this product.

Moreover, for both economic and environmental reasons, new materials and procedures have been developed in recent years that are aimed at the separation and use of proteins from by-products or from raw materials of little value. One of the separation techniques is ion exchange chromatography, which has given rise to substantial developmental research relative to new materials (Paredes et al., 2001, 2003, 2004). In the egg product industries, a highly pollutant waste results from the cracking of the shell. The waste is fundamentally made up of the shell (approximately 10\% of the weight of the hen's egg) and its corresponding membranes and residual egg white adhered to the inner surface. However, the environmental problem generated by the egg industry is not as important as the problem generated by the whey in the dairy industry; however, it must be considered so, as it represents a problem for the egg derivate industries. This residual egg white contains different proteins, such as ovalbumin (molecular weight $=45,000 \mathrm{Da}$ ), which presents good emulsifying and foaming properties (Galazka et al., 2000; Huntington and Stein, 2001). This makes it suitable for use in products in which this quality is one of the main commercial assets. The stability of foams is increased by raising the viscosity of the dispersion phase, decreasing the tension of the interfaces with the aid of foaming agents, and increasing the electrostatic charge and the elasticity of the liquid films. 
Table 1. Main physical characteristics of the synthesized resin for egg white protein separation

\begin{tabular}{|c|c|c|c|c|c|c|c|c|c|}
\hline & $\begin{array}{l}\text { Thermal } \\
\text { stability } \\
\text { limit } \\
\left({ }^{\circ} \mathrm{C}\right)\end{array}$ & $\begin{array}{l}\mathrm{D}(4,3) \\
(\mu \mathrm{m})\end{array}$ & $\begin{array}{l}\mathrm{D}(\mathrm{v}, 0.5) \\
(\mu \mathrm{m})\end{array}$ & $\begin{array}{l}\mathrm{N} \\
\text { content } \\
(\%)\end{array}$ & $\begin{array}{l}\text { Specific } \\
\text { surface } \\
\text { area } \\
\left(\mathrm{m}^{2} / \mathrm{g}\right)\end{array}$ & $\begin{array}{l}\text { Most } \\
\text { frequent } \\
\text { pore } \\
\text { diameter } \\
(\mathrm{nm})\end{array}$ & $\begin{array}{l}\text { Permeability } \\
\left(\mathrm{cm}^{2}\right)\end{array}$ & $\begin{array}{l}\text { Equilibrium } \\
\text { constant }^{1}\end{array}$ & $\begin{array}{l}\text { Protein } \\
\text { retention } \\
\text { capacity } \\
(\mathrm{mg} / \mathrm{mL})\end{array}$ \\
\hline MC/DMC resin ${ }^{2}$ & 200 & 180 & 177 & 1.74 & 63 & 12.9 & $1.5 \times 10^{-10}$ & 10 & 15 \\
\hline Q-HyperD ${ }^{3}$ & 150 & 55 & 50 & 2 & ND & $\begin{array}{l}\text { Pore filled } \\
\text { with gel }\end{array}$ & $1.0 \times 10^{-8}$ & 4 & 80 \\
\hline
\end{tabular}

${ }^{1}$ Calculated using the constant separation factor isotherm.

${ }^{2} \mathrm{MC} / \mathrm{DMC}=$ Methacrylate/dimethacrylate.

${ }^{3}$ BioSepra (Pall Corp., East Hills, NY).

From previous works carried out by the authors (Paredes et al., 2001; Suárez et al., 2002; Paredes et al., 2003) using new poly(glycidyl methacrylate-co-ethylene dimethacrylate) anionic ion exchange resins to separate, in an economic way, the proteins from wastes of food industries and employing a simple rheological study with different formulations of yogurt mousses (Paredes et al., 2004), the objectives of the present work were 1) to separate, with good efficiency and purity, the ovalbumin contained in residual egg whites from the egg product industries, and 2) to verify that the obtained ovalbumin could be incorporated into yogurt mousse without any textural and organoleptic changes to the final product. If so, this process could translate into some economical profit.

\section{MATERIALS AND METHODS}

\section{Synthesis and Characterization of the Resin}

Because commercial resins for separating proteins by ion exchange are really expensive, in this study, a poly(glycidyl methacrylate-co-ethylene dimethacrylate) resin developed by the authors was used (Paredes et al., 2001; Suárez et al., 2002; Paredes et al., 2003, 2004). Table 1 shows the values of the most important parameters of the developed resin.

The synthesized groups found in the resin are related to the nitrogen content. The result of the elemental analysis revealed a value equivalent to that of other, similar resins (Stanley et al., 1996). The main advantage of this resin is the low cost of manufacturing compared with commercial resins. For example, the cost to obtain $1 \mathrm{~g}$ of ovalbumin with the methacrylate-based resin is near $\$ 7$, and by using a commercial resin, such as Q-HyperD (BioSepra, Pall Corp., East Hills, NY), the cost is increased to $\sim \$ 7.50$. Characteristics of a good, well-tested commercial resin are also presented in Table 1 for comparison with the resin used in this work. The commercial resin presents better capacity and a lower equilibrium constant; the main disadvantage of this resin is its high economical cost and the high pressure drop when it is packed in chromatographic columns (Rendueles de la Vega et al., 1998).

\section{Prior Conditioning of the Egg White}

Hen eggs were purchased from a local market. Conditioning was carried out with the goal of removing ovomucin from the egg white; otherwise, it would interfere with the normal flow through the column. The method used was the one referred to elsewhere (Croguennec et al., 2000), which employs nontoxic reactants. The mucin-free egg white supernatant obtained was then dried at $30^{\circ} \mathrm{C}$ under vacuum in a Savant Speed Vac SPD $111 \mathrm{~V}$ device (Savant Instruments Inc., Holbrook, NY) until its use.

\section{Chromatography and Electrophoretic Characterization}

The separation of ovalbumin was carried out on a column scale using the techniques indicated previously. The yield was similar to that obtained by others employing commercial products (Vachier et al., 1995; Shibusana et al., 1998; Awadé and Efstathiou, 1999; Croguennec et al., 2000). The fixed bed-scale trials were conducted using a 32-mm internal diameter Vantage borosilicate glass column (Millipore Bioprocess Division, Stonehouse, UK) loaded by dynamic compression (Stanley et al., 1996) with $23 \mathrm{~mL}$ of resin, presenting a final density of $0.43 \mathrm{~g} / \mathrm{mL}$. The solution, introduced by means of a Masterflex 7554-60 peristaltic pump (Cole Palmer Instruments Co., Chicago, IL), had a concentration of $5 \mathrm{mg} / \mathrm{mL}$ and was buffered in Tris $\cdot \mathrm{HCl} 10 \mathrm{mM}$ (pH 7.6). Stepwise gradient elution was carried out employing a solution of $0.5 \mathrm{M} \mathrm{NaCl}$. After the final elution, the column was washed with 5 vol of said solution (Panreac, Montplet and Esteban S.A., Barcelona, Spain) and was then reconditioned using the Tris $\cdot \mathrm{HCl} 10 \mathrm{mM}$ buffer $(\mathrm{pH}$ 7.6). The concentration of proteins at the column outlet was analyzed by means of an Rd UV- 
1203 spectrophotometer (Shimadzu Europe GmbH, Duisburg, Germany) working at $280 \mathrm{~nm}$.

The separated egg white proteins were dried at $30^{\circ} \mathrm{C}$ under a high vacuum in the Speed Vac SPD $111 \mathrm{~V}$ device and afterward was identified by electrophoresis. This procedure was completed via the SDS-PAGE technique with a Mini Protean 3 device (BioRad Laboratories, Hercules, CA) using $6.8 \%$ concentration gel and $14 \%$ separation gel. The $15-\mu \mathrm{L}$ samples were used with an approximate concentration of $2 \mu \mathrm{g} / \mathrm{mL}$.

\section{Use of Ovalbumin Obtained in the Elaboration of Yogurt Mousse}

On the basis of the results of previous research carried out with commercial products (Paredes et al., 2004), a formulation and elaboration process of a similar product was developed at laboratory scale with the aim of verifying that the previously obtained ovalbumin can be incorporated to yogurt mousse without important organoleptic and textural effects. If so, economic profit could result.

Because no information from a company is passed along relative to its products' formulation and elaboration processes, formulation was conducted at laboratory scale to obtain, in any case, a product with the most similar characteristics and composition $(4.7 \mathrm{~g}$ of protein, $14.5 \mathrm{~g}$ of carbohydrates, and $9.3 \mathrm{~g}$ of fat; all per 100 -g sample; $\mathrm{pH} 4.30$ ) to the top brand name in the market. For the product containing ovalbumin, some components-mainly those of fats and yogurt-were incorporated in different ways to facilitate the integration and final desired effect of ovalbumin. The quantity of ovalbumin finally used $(1.3 \%$, wt $/ \mathrm{wt}$ ) was decided on the basis of previous tests developed by the authors. In any case, both products, without and with ovalbumin, had the same final composition.

Elaboration Method: Product Without Ovalbumin. With this product, a low quantity of sugared yogurt was used as culture during the elaboration process. Eight-five milliliters of pasteurized whole milk, $15 \mathrm{~mL}$ of sugared yogurt (used as culture; $3.5 \mathrm{~g}$ of protein, $14.5 \mathrm{~g}$ of carbohydrates, and $1.8 \mathrm{~g}$ of fat $/ 100 \mathrm{~g}$ ), and $75 \mathrm{~mL}$ of $30 \%$ cream were incubated at $40^{\circ} \mathrm{C}$ for 7 $\mathrm{h}$. The mixture was cooled to $6^{\circ} \mathrm{C}$ and left to stand for $12 \mathrm{~h}$. It was then whipped with $21 \mathrm{~g}$ of sugar in the presence of $2.5 \mathrm{~g}(1.1 \%$, wt/wt) of powdered gelatine (Royal United Biscuits Iberia S.L., Barcelona, Spain) previously prepared in $30 \mathrm{~mL}$ of water at $80^{\circ} \mathrm{C}$. The product was finally packed in yogurt cartons and stored at $6^{\circ} \mathrm{C}$.

Elaboration Method: Product With Ovalbumin Incorporated. Fifty milliliters of pasteurized whole milk, $8 \mathrm{~g}$ of powdered milk, $3.1 \mathrm{~g}$ of pure ovalbumin
$(1.3 \%, \mathrm{wt} / \mathrm{wt}), 50 \mathrm{~mL}$ of the sugared yogurt, $60 \mathrm{~mL}$ of $30 \%$ cream, and $5 \mathrm{~g}$ of margarine were mixed together and incubated at $40^{\circ} \mathrm{C}$ for $6 \mathrm{~h}$ with the subsequent evolution in $\mathrm{pH}$. The mix was cooled to $8^{\circ} \mathrm{C}$ for $24 \mathrm{~h}$, after which time the final $\mathrm{pH}$ was 4.70 . Drops of citric acid solution (Probus S.A., Badalona, Barcelona, Spain) were added until a $\mathrm{pH}$ of 4.2 was obtained; then, the mix was whipped after adding $21 \mathrm{~g}$ of sugar and $2.5 \mathrm{~g}$ $(1.1 \%, \mathrm{wt} / \mathrm{wt})$ of powdered gelatine in $30 \mathrm{~mL}$ of hot water at $80^{\circ} \mathrm{C}$. The product was finally packed in yogurt cartons and stored at $6^{\circ} \mathrm{C}$. Final $\mathrm{pH}$ was 4.4. The inclusion of margarine facilitates the integration of the ovalbumin. Citric acid had to be added to regulate $\mathrm{pH}$ and prevent undesired odors.

\section{Rheometric Determinations}

Substances, such as yogurt mousse, present different textural properties that are characteristic of elastic and viscous bodies, and the extension of both behaviors may be studied by means of rheometry. Thus, a phase displacement angle $(\delta)$ or phase change angle is defined. The tangent of this angle $\delta$ is $\tan \delta=\mathrm{G}^{\prime \prime} / \mathrm{G}^{\prime}\left(\mathbf{G}^{\prime \prime}=\right.$ viscous modulus; $\mathbf{G}^{\prime}=$ elastic modulus), and it is usually called the loss tangent (Steffe, 1996). When the angle $\delta$ is related to stress and oscillatory deformation, the following functions are obtained

$$
\mathrm{G}^{\prime}=\mathrm{G}^{*} \cos \delta \mathrm{G}^{\prime \prime}=\mathrm{G}^{*} \sin \delta
$$

such that in a perfect elastic system, $\delta=0^{\circ}$ and $\tan \delta=$ 0 , and in a perfect viscous system, $\delta=90^{\circ}$ and tan $\delta=\infty$. Under conditions of $\tan \delta=0$, all of the energy generated is recovered; in a viscous system, $\delta=90^{\circ}, \mathrm{G}^{\prime}=$ 0 , and $G^{\prime \prime}$ takes the maximum value. $G^{*}$ is a viscoelastic coefficient whose value is $\tau_{0} / \mathbf{y}_{0}$, where $\tau_{0}$ represents the stress for a deformation amplitude, $\mathrm{y}_{0}$. These parameters may be determined using modern rheometers by means of static and oscillatory tests.

In the present study, which was aimed to determine the rheological properties of yogurt mousse, a Haake RS50 RheoStress rheometer equipped with a Searletype measuring system (Gebrüder Haake GmbH, Karlsruhe, Germany) was used; to such, a toroidal sleeve, designed by the authors, was added to avoid evaporation of the sample. Both static and dynamic tests were carried out to characterize the products under study. First, the ideal working intervals were determined, conducting tests in duplicate to ensure the reproducibility of the obtained results. The measuring sensor used was of the plate-plate type. The temperature of the room was maintained at $20^{\circ} \mathrm{C}$ by means of air conditioning. Determinations were carried out at $5^{\circ} \mathrm{C}$; this temperature was maintained by the device's cryostat. It was 
subsequently verified that the results at this temperature allowed the same conclusions to be maintained at least up until a temperature of $15^{\circ} \mathrm{C}$; these 2 temperatures constitute a reasonable consumption interval for the product.

In the static creep and recovery tests, a constant stress of $\tau=20 \mathrm{~Pa}$ was applied over a period of $180 \mathrm{~s}$, to study the progressive evolution of deformation. In the second phase, the shear stress was removed, and we observed how this energy, which is accumulated by the elastic component, is capable of recovering, over a period of $300 \mathrm{~s}$, a certain percentage of the initial form of the fluid. To experimentally estimate the yield stress value, the samples were subjected to an increasing stress ramp, from 2 to $350 \mathrm{~Pa}$. The stress at which each sample changes from being fundamentally elastic to being fundamentally viscous is determined on the basis of the nature of the sample. This point coincides with a decrease in the value of $\eta$.

Three types of forced oscillation tests were conducted.

Stress Sweeps. The predominant component for each stress is studied, i.e., elastic or viscous. The range of stress applied to the sample is determined, i.e., where its viscoelastic characteristics are affected the least, to maintain linearity. This point represents the position at which the magnitude of the elastic and viscous modulus remains constant and independent of the stress. To do so, the samples were subjected to an increasing stress sweep, from 2 to a maximum of $300 \mathrm{~Pa}$, depending on the nature of each sample. The oscillatory frequency used was $1 \mathrm{~Hz}$. All of the tests were carried out at constant conditions and a temperature of 5 to $15^{\circ} \mathrm{C}$.

Frequency Sweeps. Once the stress sweeps had been carried out and the range of linearity for the samples was determined, these were subjected to a constant stress within this range of linearity. The stress used was $50 \mathrm{~Pa}$, and the frequency ramp now used was 0.464 to $10 \mathrm{~Hz}$.

Temperature Ramp. Within the range of linearity determined using the just-mentioned tests, a shear stress, $50 \mathrm{~Pa}$, and a specific frequency, $1 \mathrm{~Hz}$, were selected and a temperature ramp of 5 to $15^{\circ} \mathrm{C}$ was established to observe the influence of temperature on the behavior of the samples. The chosen ramp was $0.8^{\circ} \mathrm{C} /$ min, which is the maximum permitted by the device's cryostat.

\section{Sensorial Determinations and Other Characterization Tests}

These tests were carried out to verify the absence of divergence with the results of the rheological measurements.
Sensorial Assessment. The affective preference method (Andalzúa, 1994) was used in the organoleptic assessment. A matrix was designed for the productevaluating sheets and the following methodological aspects were established.

- Definition of the organoleptic qualities to assess and their weighting in the final score. The qualities of appearance, texture, and odor or flavor were fixed with a weighting of 30,40 , and $30 \%$, respectively.

- Definition of the attributes to evaluate in each quality

- Appearance via the color and appearance when cut with a spoon $(15+15 \%)$

- Texture via the mechanical resistance on the spoon and in the mouth and the adherence and stickiness in the mouth and on the palate $(10+15+15 \%)$

- Odor or flavor via independent basic odor and flavor tests and aroma (bouquet) tests on the palate $(10+10+10 \%)$.

- Establishment of the pursued organoleptic standard or target for the product. The organoleptic targets established for these attributes were those of a leading product of a leading brand name on the European market.

- Definition of the defects and the degree to which these affect the attributes. A total maximum score of 10 points was established for the attributes. To assign a score to each attribute, its assessment was divided into 5 equal parts, and a score was assigned according to the following scoring criterion: lowest score $=$ attribute is very deficient or very far below the standard; low mark = attribute is far below the standard; average score $=$ attribute is average; high score $=$ attribute is close to the standard; highest score $=$ attribute corresponds fully to the standard.

- Definition of the methodology to use in the organoleptic assessment of attributes. The panel was duly instructed about said methodology and in particular concerning the ways of avoiding physiological and environmental causes that might condition the results.

- Panel. The panel was composed of 8 healthy subjects between 25 and $40 \mathrm{yr}$ of age without any sensorial defects. Subjects were chosen via taste and olfactory tests from among the laboratory staff. These panelists were trained prior to commencement of the test in basic tasting procedures, including sampling times, mouth washes, time intervals between samples, and presentation of the data on the scoring sheet. The panelists were also trained and familiarized with different types of yogurt mousses to be able to detect the differences in the products.

- Test conditions. The test was conducted in a room next to the laboratory with artificial lighting, during 
the early afternoon, with a room temperature of $20^{\circ} \mathrm{C}$ and $80 \%$ humidity in isolated work stations free from noise.

- Description of the samples. Yogurt mousses without and with ovalbumin were prepared in the laboratory by the method presented previously within $7 \mathrm{~d}$ prior to the tests. Products were conserved in the refrigerator at $5^{\circ} \mathrm{C}$.

- Sample preparation. The samples (2 for each product) were presented in commercial mousse cartons without any label or brand name and were numbered 1 to 4 . They were scored in one single day at a temperature of $\sim 10^{\circ} \mathrm{C}$.

- Data analysis. The average result of the 2 samples was taken as the score for each attribute of each product. Once calculated for each member of the panel, the final score was obtained by averaging the results for each attribute across all panel members. Values with deviations of $>20 \%$ were not taken into account. Three replicates of the tests were carried out, and a statistical ANOVA method was used to determine the confidence interval of the results.

Other Characterization Tests of the Assessed Products. The following tests were also conducted on the samples.

- Yield. The volume of a given weight of mousse (mL/ g) was determined. This was carried out in a special $100-\mathrm{cm}^{3}$ flask that was filled to the top with the sample, leveled, and then weighed. The average of 3 tests was obtained. An ANOVA method was used also in this part to determine the confidence interval of the results.

- Stability. Loss in volume with time under the effect of centrifugal forces was tested. A given amount of the product was subjected to centrifugation under standard conditions with the goal of determining its loss in volume in the form of air. Standard tubes containing the sample were centrifuged for $12 \mathrm{~min}$ at $9,500 \times g$ at $15^{\circ} \mathrm{C}$ in a Kubota 6700 centrifuge (Kubota Corp., Osaka, Japan), and subsequently, the value of the reduction in volume of the sample was measured. The average of 3 tests was obtained.

- $\mathrm{pH}$. This was measured at $15^{\circ} \mathrm{C}$ using a MicropH 2001 pHmeter (Crison Instruments S. A., Barcelona, Spain).

\section{RESULTS AND DISCUSSION}

\section{Separation of Egg White Ovalbumin by Anion Exchange Chromatography for its Use in the Elaboration of Yogurt Mousse}

Once protein load capacity of the resin and its volume had been determined, the packed column was loaded

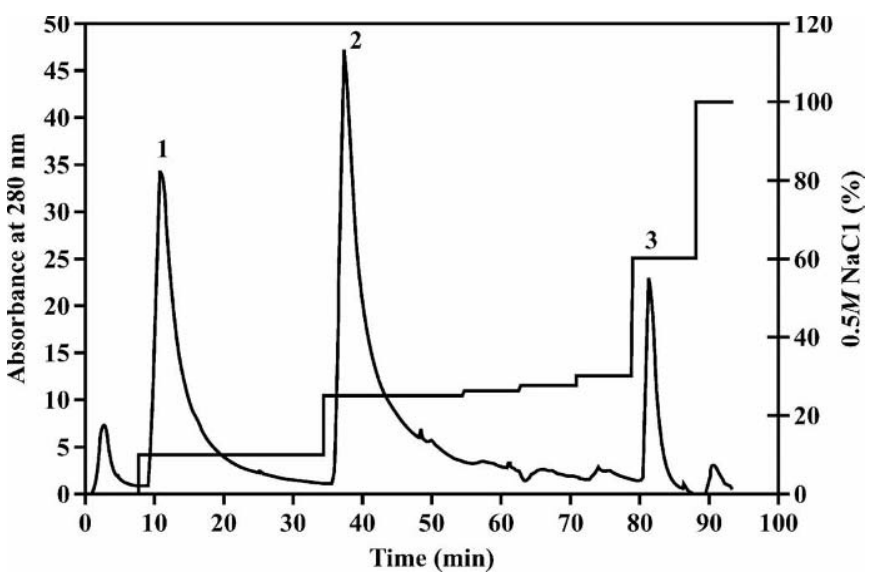

Figure 1. Step gradient chromatogram of egg white sample.

with a solution, the total protein content of which was around $90 \%$ of its total capacity. Elution of the retained proteins was carried out using a solution of $0.5 \mathrm{M} \mathrm{NaCl}$. It was observed that, in a first elution step, at a concentration of $0.05 \mathrm{M} \mathrm{NaCl}$, a part of the egg white proteins could be separated (peak 1; Figure 1). A second step was carried out with $0.15 \mathrm{M} \mathrm{NaCl}$ (peak 2; Figure 1), where ovalbumin was the main protein present, but some impurities were observed. In a final step, at 0.3 $M \mathrm{NaCl}$, a selective elution of ovalbumin was achieved (peak 3; Figure 1). To ensure the cleanliness of the column for the subsequent experiment, $0.5 \mathrm{M} \mathrm{NaCl}$ was used as a second step. This resulted in equally successful elution of the ovalbumin, ensuring full regeneration of the resin. An initial little peak eluted without $\mathrm{NaCl}$ can also be seen in Figure 1 that includes nonretained substances. As regards the corresponding electrophoresis (Figure 2), lane 1 corresponds mainly to the trypsine inhibitor, lane 2 of the gel corresponds to the $0.15 \mathrm{M}$ $\mathrm{NaCl}$ gradient in which the proteins ovotransferrine and ovalbumin are found, and lane 3 is occupied by practically pure ovalbumin. The yield of the ovalbumin separated was $83 \%$ with respect to the initial content of ovalbumin of the treated egg white.

\section{Rheological Measurements of the Mousses without and with Ovalbumin}

Creep and Recovery Tests at 5 and $15^{\circ} \mathrm{C}$. These tests provide an initial approximation of the values of the elastic and viscous components in samples of a viscoelastic nature. The results obtained with the samples without and with ovalbumin are presented in Figure 3.

The shape of the curves is a good fit to that corresponding to the 4-element Burgers model for viscoelastic substances (Schramm, 1994; Steffe, 1996). A greater 


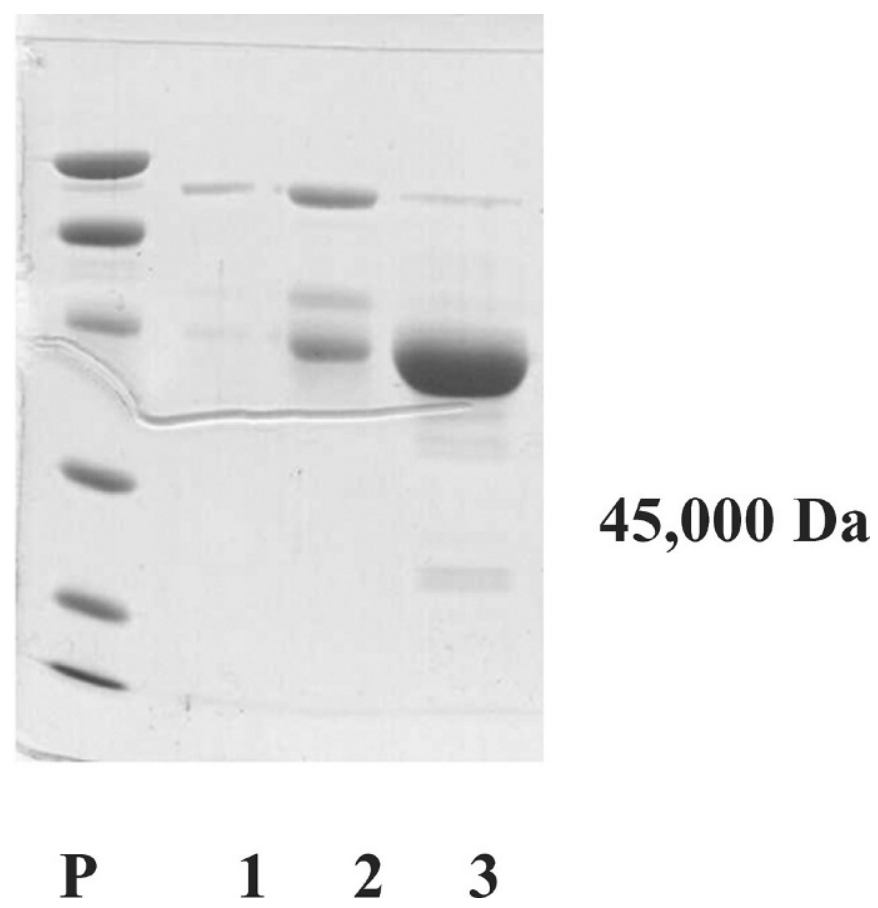

Figure 2. PAGE-SDS gel corresponding to the former chromatogram. Lane $\mathrm{P}=$ molecular weight standard; lanes 1,2 , and 3 correspond to peaks 1,2 , and 3 in Figure 1. elastic component is observed in all samples at both temperatures. At $5^{\circ} \mathrm{C}$, the sample without ovalbumin recovers approximately $65 \%$ of its initial form; with ovalbumin, recovery increases up to $75 \%$, corresponding to the greater elastic behavior of the latter, fundamentally because of the foaming effect of the added protein. As expected, elasticity always decreases at $15^{\circ} \mathrm{C}$, the sample with ovalbumin recovered to $72 \%$. Therefore, the differences are not very important, which suggests that the incorporation of ovalbumin neutralizes slightly the adverse effect on elasticity when the temperature increases from 5 to $15^{\circ} \mathrm{C}$, as found in the product without ovalbumin. The product with ovalbumin maintains the rheological characteristics in the temperature range tested in this work.

Prior Dynamic Flow Tests: Yield Stress and Viscosity Drop at $5^{\circ} \mathrm{C}$. The corresponding yield stress and viscosity drop graphs obtained at $5^{\circ} \mathrm{C}$ for the samples without and with ovalbumin are presented in Figures 4 and 5 . It can be seen that the product with ovalbumin shows a greater resistance to deformation under increasing shear stress (Figure 4). It can be seen that without ovalbumin, the value of strain reaches its peak at a stress of almost $250 \mathrm{~Pa}$. However, in the case of the sample with ovalbumin, the required stress to reach the peak strain is $300 \mathrm{~Pa}$. The behavior is linear in both samples $<100 \mathrm{~Pa}$. The behavior, with respect to viscosity (Figure 5), is similar in both cases. These tests, together

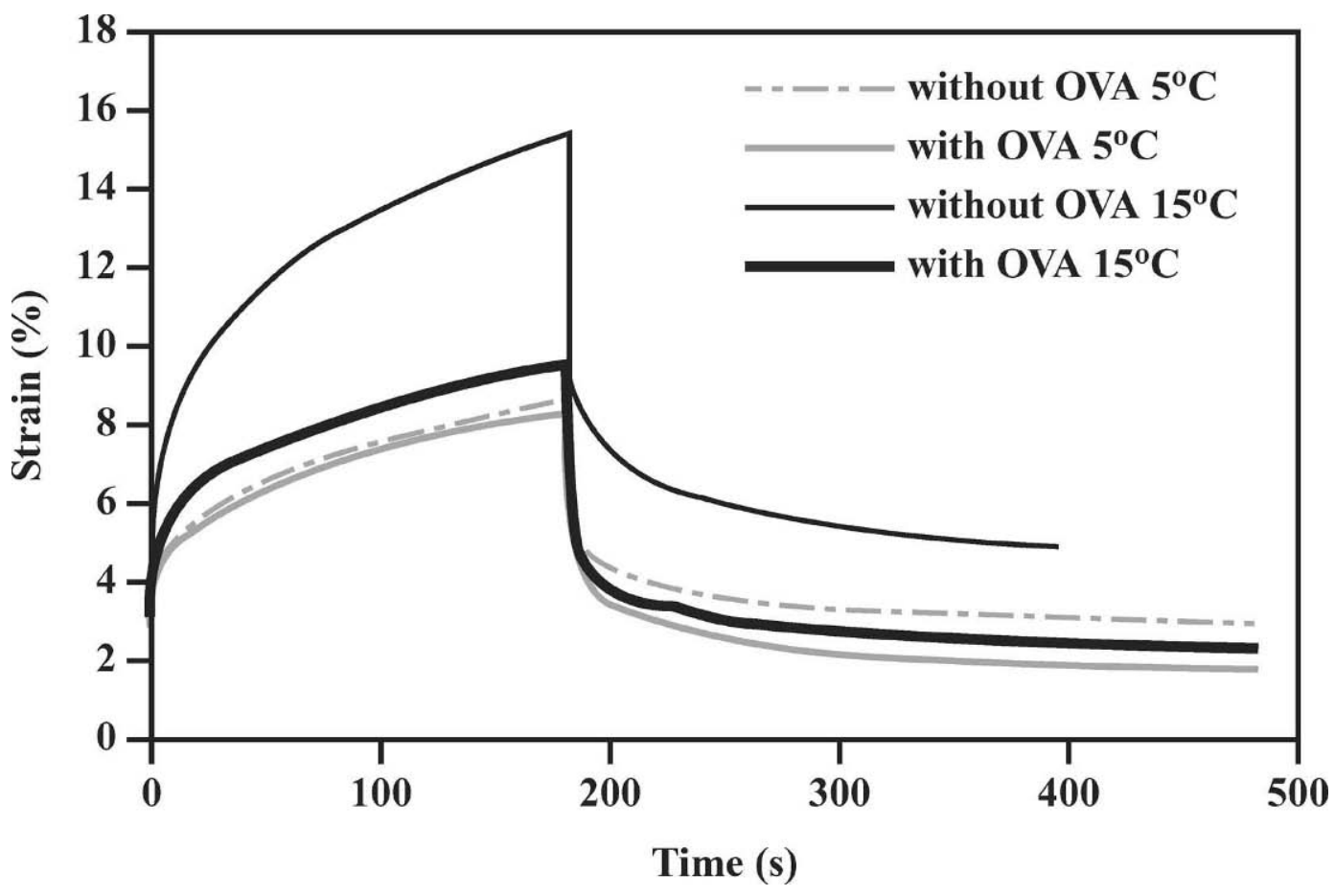

Figure 3. Creeps and recovery tests corresponding to samples with and without ovalbumin (OVA) at 5 and $15^{\circ} \mathrm{C}$. 


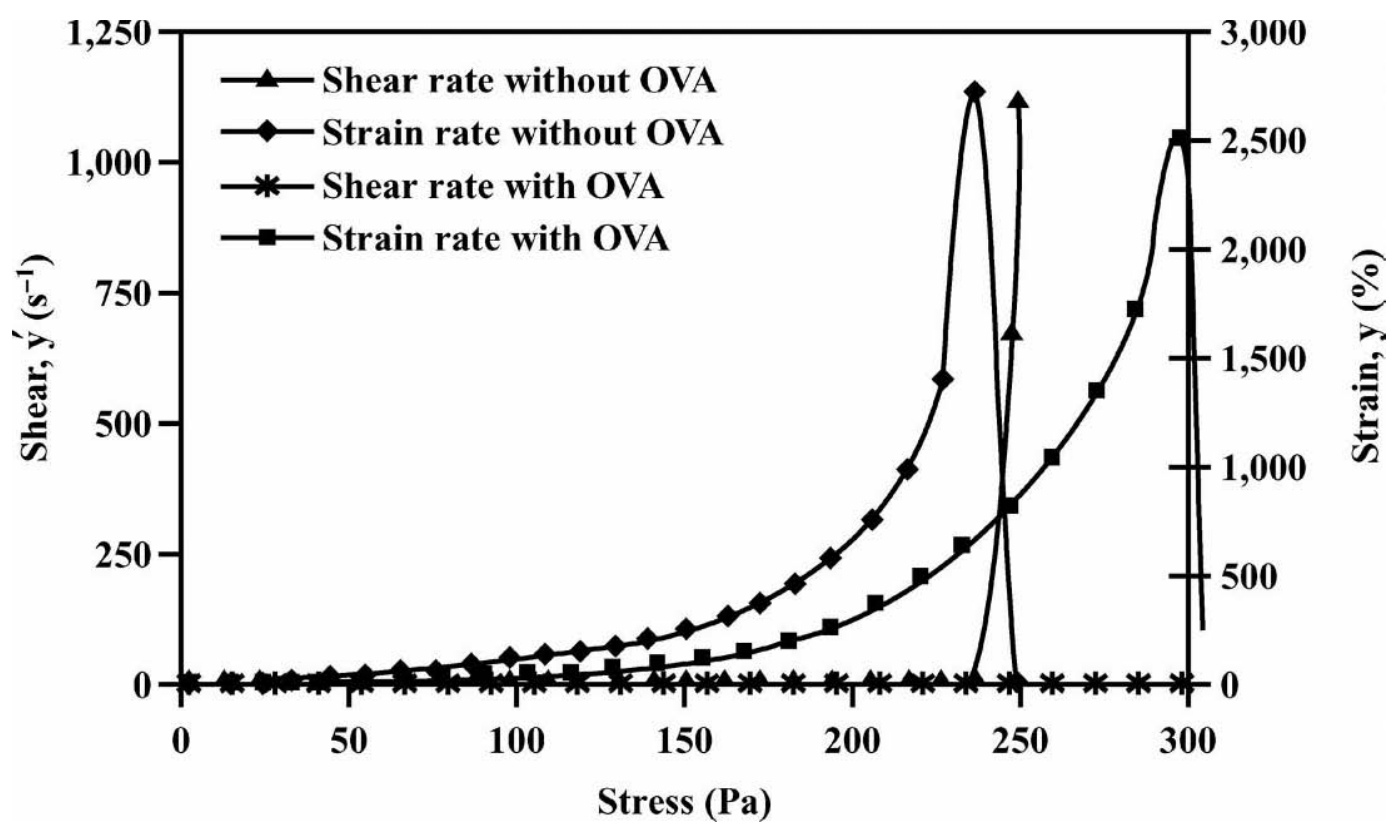

Figure 4. Yield stress at $5^{\circ} \mathrm{C}$ for samples with and without ovalbumin (OVA).

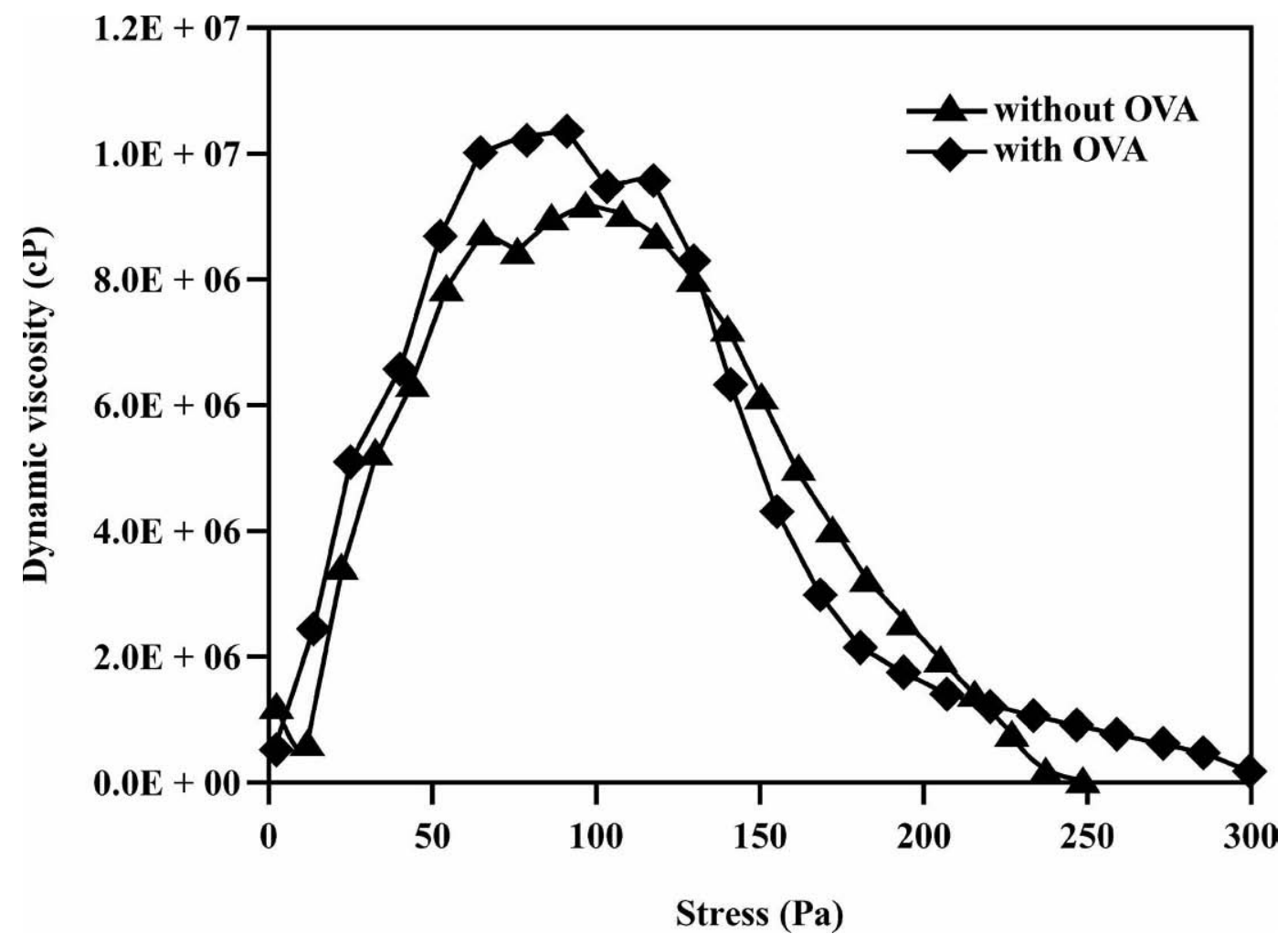

Figure 5. Viscosity drop at $5^{\circ} \mathrm{C}$ for samples with and without ovalbumin (OVA). 


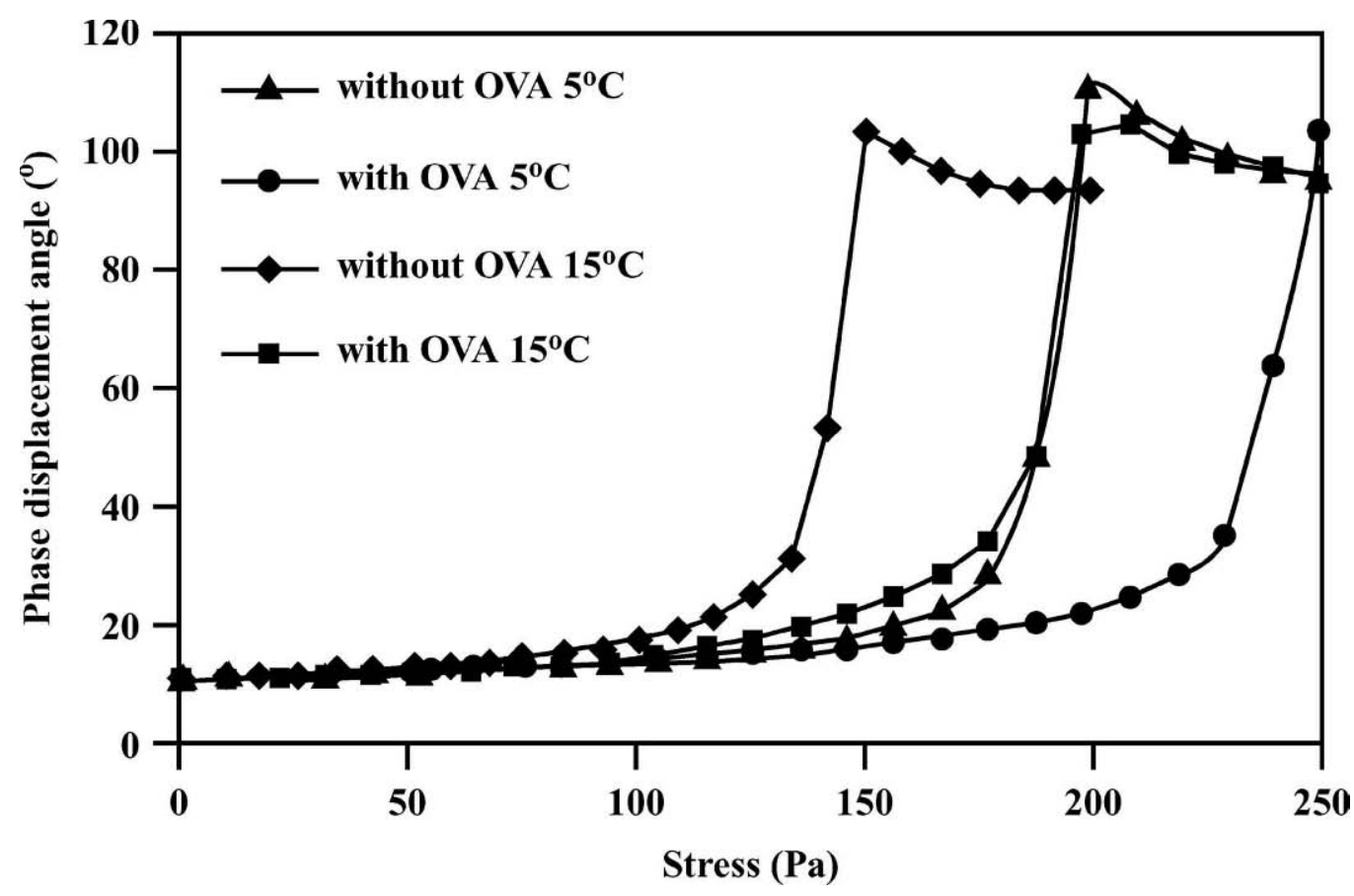

Figure 6. Stress scanning. Phase displacement angles at 5 and $15^{\circ} \mathrm{C}$ for samples with and without ovalbumin (OVA).

with the stress sweeps, allowed the intervals of linear behavior of the analyzed samples to be established.

Forced oscillation tests were similarly carried out to determine the degree of the elastic and viscous components of the respective products at the assayed temperatures. The most noteworthy aspects of the obtained results are discussed subsequently.

Dynamic Tests, Forced Oscillation Tests, and Stress Sweeps. These tests allow the range of linear behavior of the product to be determined. Figure 6 presents the results obtained at $5^{\circ} \mathrm{C}$. It can be seen that the presence of ovalbumin gives greater values of $\mathrm{G}^{\prime}$ to the samples for a particular stress than those presented by the sample without ovalbumin, i.e., it makes the sample more resistant to creep. As the values of $G^{\prime \prime}$ remain similar, it may be stated that the presence of ovalbumin makes the product more elastic within the studied stress range, as its phase displacement angle, $\delta$, is smaller.

To ensure once more that similar behavior is maintained at $15^{\circ} \mathrm{C}$, the tests were repeated at this temperature. Figure 7 shows the compared values obtained in these tests at 5 and $15^{\circ} \mathrm{C}$ for the calculated values of phase displacement angle vs. stress in samples without and with ovalbumin. It can be seen that at $5^{\circ} \mathrm{C}$, the samples present a phase displacement angle close to $15^{\circ}$ in the area of viscoelastic linearity (marked elastic character). The value of the phase displacement angle increases drastically from a stress close to $200 \mathrm{~Pa}$ in the sample without ovalbumin, whereas in the sample with ovalbumin, this increase is produced from a stress close to $250 \mathrm{~Pa}$. Once again, the sample with ovalbumin is more resistant to deformation than the sample without ovalbumin.

At $15^{\circ} \mathrm{C}$, it can be seen that the samples present a phase displacement angle close to $20^{\circ}$, which corresponds to the expected slight increase in the viscous component of the product in the area of viscoelastic linearity, which is caused by the increase in temperature, although the predominantly elastic character of the product is maintained. The phase displacement angle increases drastically from a stress close to 150 $\mathrm{Pa}$ in the sample without ovalbumin, whereas in the sample with ovalbumin, this increase is produced from a stress close to $200 \mathrm{~Pa}$. Yet again, the sample with ovalbumin is more resistant to deformation than the sample without ovalbumin.

Dynamic Tests, Forced Oscillation Tests, and Frequency Sweeps. Because the value of the phase displacement angle and of $\mathrm{G}^{*}=\mathrm{G}^{\prime}+\mathrm{i} \cdot \mathrm{G}^{\prime \prime}$ depend on the angular frequency used in the oscillatory test, it is of interest to verify the influence of this value and the possible practical consequences of said influence. Figure 7 presents the results obtained at $5^{\circ} \mathrm{C}$. The similarity of the values of $G^{\prime}$ and $G^{\prime \prime}$ can be seen in this case for the samples without and with ovalbumin.

To ensure once more that the similar behavior is maintained at $15^{\circ} \mathrm{C}$, the tests were repeated at this 


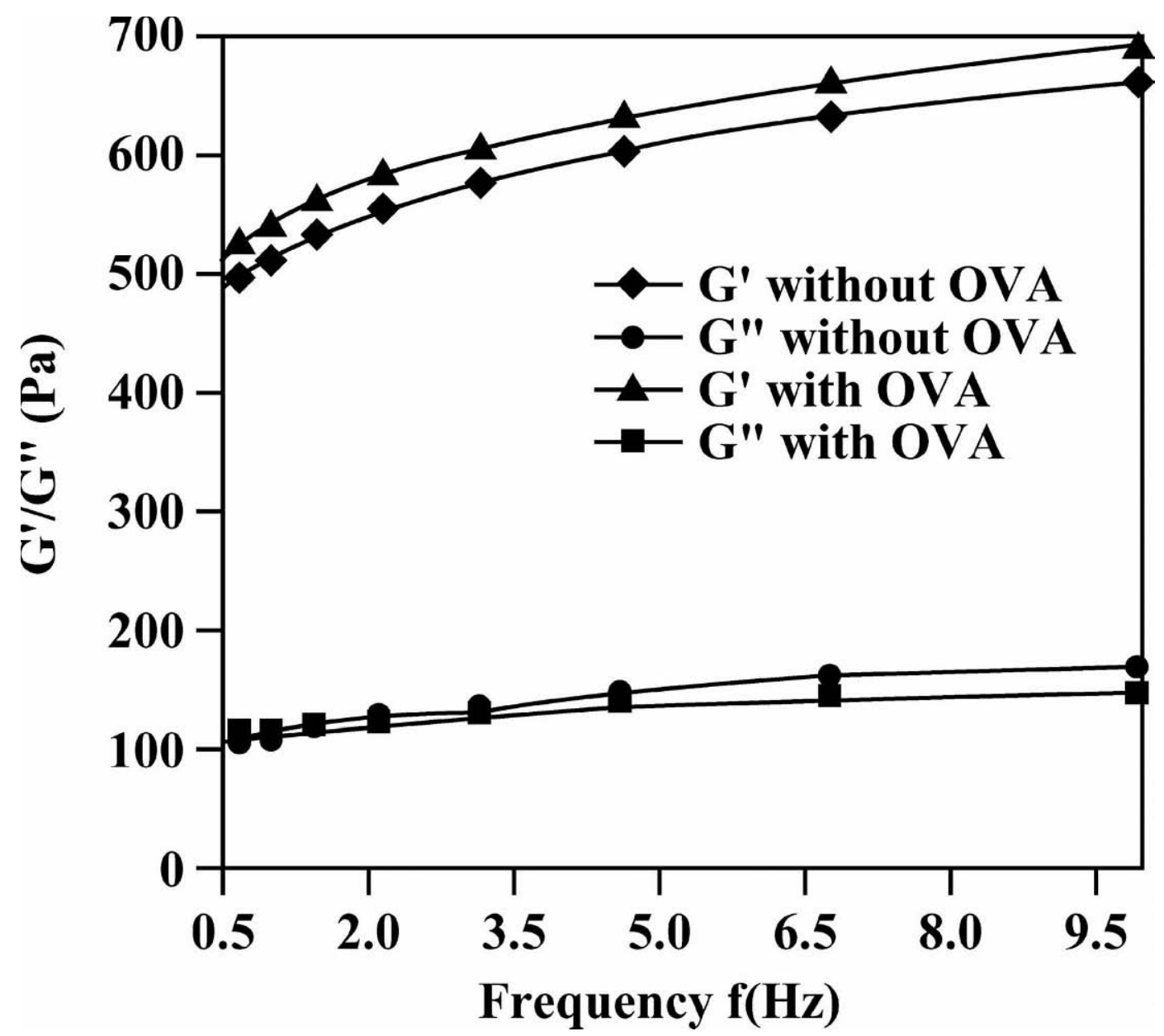

Figure 7. Storage modulus $\left(\mathrm{G}^{\prime}\right)$ and loss modulus $\left(\mathrm{G}^{\prime \prime}\right)$ values at $5^{\circ} \mathrm{C}$ for samples with and without ovalbumin (OVA).

temperature. Figure 8 shows the compared values obtained in these tests at 5 and $15^{\circ} \mathrm{C}$ for the calculated values of phase displacement angle vs. angular frequency in the samples without and with ovalbumin. It can be seen that at $5^{\circ} \mathrm{C}$, the samples present a phase displacement angle just over $10^{\circ}$, and $\mathrm{G}^{\prime}$ is greater than the loss of $G^{\prime \prime}$. As expected, when the temperature is raised to $15^{\circ} \mathrm{C}$, the phase displacement angle is somewhat greater, resulting in a slight drop in the elastic character of the product. With regard to the complex coefficient, $G^{*}=G^{\prime}+i \cdot G^{\prime \prime}$, this is also greater in the sample with ovalbumin.

Dynamic Tests. Forced Oscillation Tests. Temperature Ramps Between 5 and $15^{\circ} \mathrm{C}$. This test allowed us to monitor the evolution of the rheological properties during heating of the product, which occurs to a greater or lesser degree in practice from the moment when a carton is taken out of the refrigerator until we finish consuming it. The assays were carried out within a temperature interval between 5 and $15^{\circ} \mathrm{C}$, establishing a ramp of $0.8^{\circ} \mathrm{C} / \mathrm{min}$ between the 2 values in the equipment (see Materials and Methods) and allowing a reasonable margin of 10 to 12 min for this variation in temperature to take place. Similarly, the chosen value of a constant stress of $50 \mathrm{~Pa}$ falls within the range of stress produced by a dessert spoon. The results are shown in Figure 9. It should be noted that within the studied temperature interval, there is no appreciable difference in the behavior of the samples. Moreover, these are within the area of linear viscoelasticity for the whole temperature ramp. The storage modulus is greater than the loss modulus in all cases, which indicates the stable and more elastic component of the samples within this temperature range.

\section{Sensorial Assessment and Other Determinations in the Developed Mousses}

Organoleptic Qualities. The results of the overall scores obtained in each case are shown in Table 2. In 


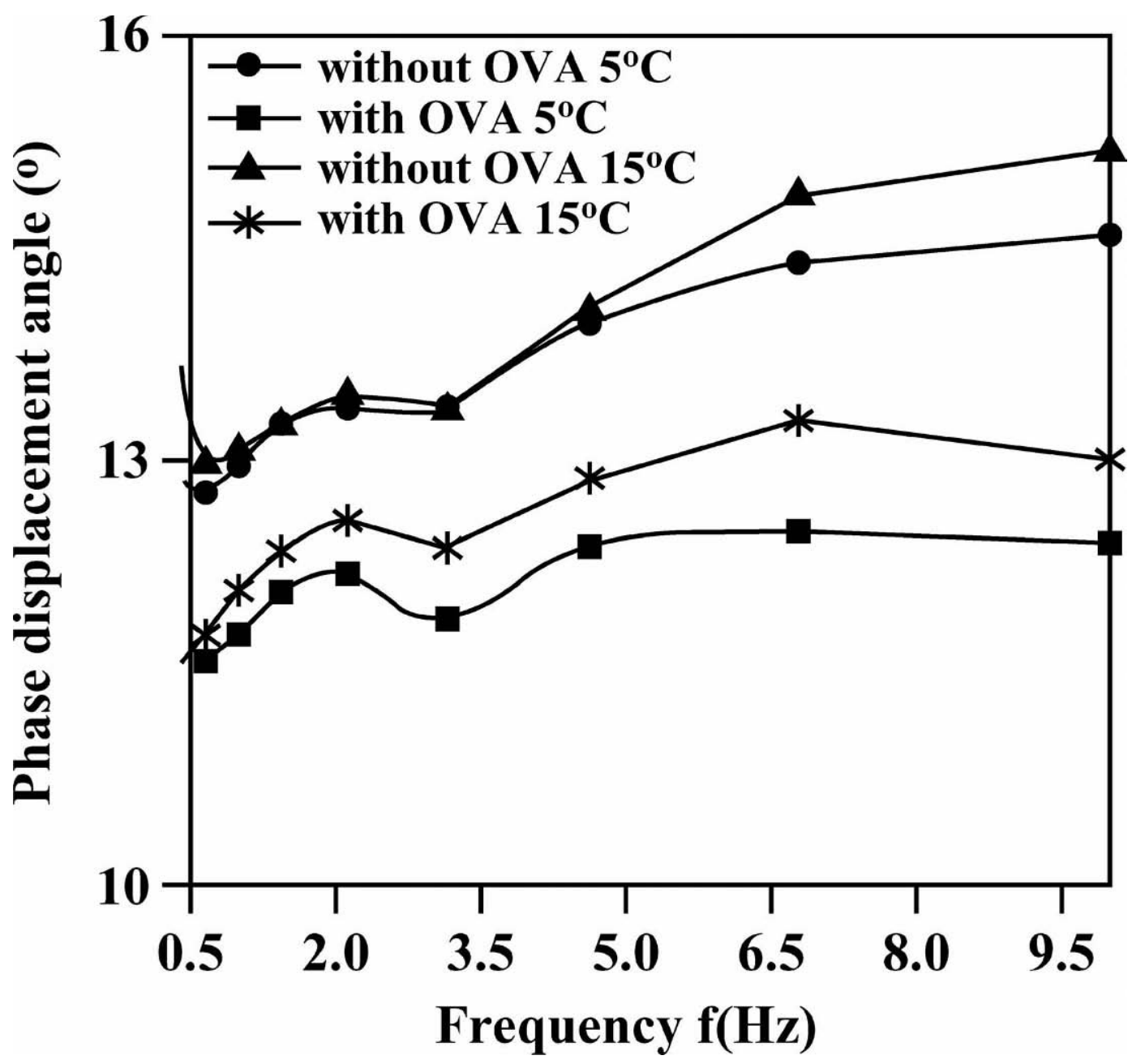

Figure 8. Frequency scanning. Phase displacement angles at 5 and $15^{\circ} \mathrm{C}$ for samples with and without ovalbumin (OVA).

this case, the values are the average of the evaluations of 8 people over 3 evaluation sessions. An error of $\sim 5 \%$ was determined.

Concerning the results, it should be noted that the texture of the product with ovalbumin obtains a relative better score, but the differences in the results are next to the experimental error of the determinations, which is in keeping with the results of the rheological measurements that attribute greater elasticity to this product. It can also be seen that the presence of ovalbumin increases the stickiness of the product, which may be explained by taking into account not only the foaming qualities of the protein but also its emulsifying properties. At the same time, however, the presence of ovalbumin produces odors and flavors that are scored lower. This fact is related to the increase in $\mathrm{pH}$ produced by the addition of ovalbumin, which was subsequently avoided by the use, in the final formulation, of an acidity corrector (citric acid), which adjusted the $\mathrm{pH}$ to ade- quate values between 4.2 and 4.5 (see previous). Another organoleptic assessment of the final formulation with citric acid added obtained a score of 7.56, indicating that the use of ovalbumin under these conditions hardly affects the final score. Conversely, the viscoelastic properties hardly suffer any variation between 5 and $15^{\circ} \mathrm{C}$, which are the estimated extreme conditions of consumption and the range within which the sensorial assessment took place.

Yield and Stability. Previous tests were carried out to find the optimal quantity of ovalbumin that should be added to mousse. Percentages tested included 0, 0.5, $1,1.3,1.5$ and $2 \%$ ovalbumin; the best percentage was 1.3 , as higher ovalbumin content begins to be detected in the taste and lower contents are not economically profitable.

The average results of yield are given in Table 3 . It can be seen that the product with ovalbumin increases its yield by approximately $7.3 \%$ with respect to the 


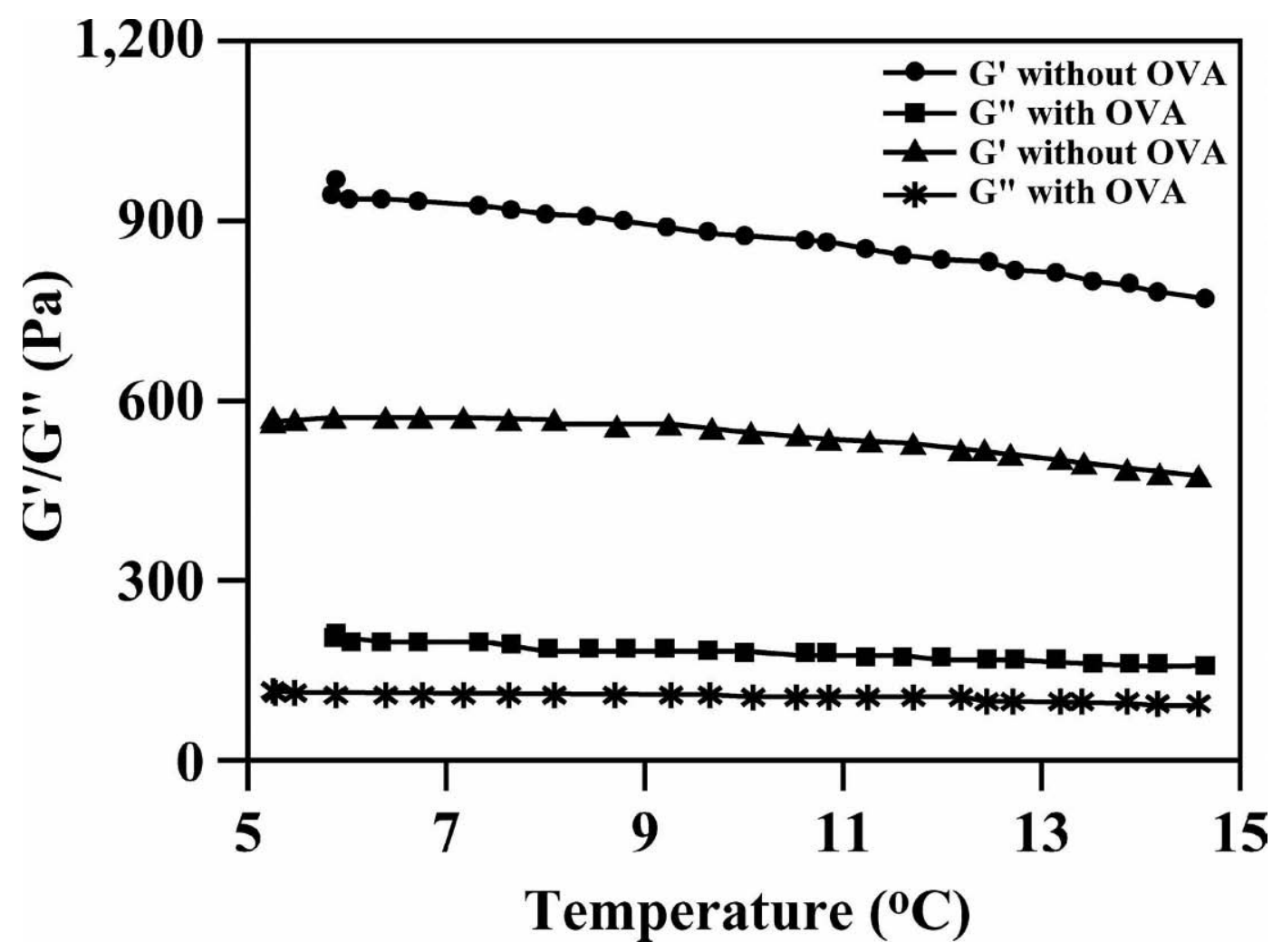

Figure 9. Storage modulus $\left(G^{\prime}\right)$ and loss modulus $\left(G^{\prime \prime}\right)$ values for temperature scanning for samples with and without ovalbumin $(O V A)$.

product without the protein. This value was always $>5 \%$ in all of the assays carried out. The stability tests showed a slight reduction in volume in the sample with ovalbumin under the aforementioned conditions of centrifugation, which may also be explained by its greater content in air. Thus, it may be stated that ovalbumin, in the amount used, increases the yield and elasticity of the product without appreciably increasing its instability.

\section{CONCLUSIONS}

Egg white ovalbumin was separated by anion exchange chromatography using an anionic exchange resin based in a methacrylate polymer matrix developed by the authors. With the aim of developing and evaluating the effects of the application of the separated and purified ovalbumin on the elaboration of yogurt mousse, samples developed for this purpose were characterized by rheological methods and compared with yogurt mousse manufactured without ovalbumin. The results of the tests carried out at 5 and $15^{\circ} \mathrm{C}$ show that yogurt mousse with ovalbumin addition follows similar behavior compared with that of mousse without ovalbumin. Moreover, the qualities of the organoleptic-evaluated products suffer hardly any variation between 5 and $15^{\circ} \mathrm{C}$, thus confirming this temperature range as good for consumption. In the developed formulations,

Table 2. Results of yogurt mousse sensorial assessment

\begin{tabular}{|c|c|c|c|c|c|c|c|c|c|}
\hline \multirow{3}{*}{$\begin{array}{l}\text { Character } \\
\text { attribute }\end{array}$} & \multicolumn{2}{|c|}{ Aspect } & \multicolumn{3}{|c|}{ Texture } & \multirow{2}{*}{\multicolumn{4}{|c|}{ Smell and taste }} \\
\hline & & Cross- & Mechanical & & & & & & \\
\hline & Color & section & characteristics & Stickiness & Adhesion & Odor & Flavor & Aroma & Total \\
\hline \multicolumn{10}{|l|}{ Top value } \\
\hline Sample $1^{1}$ & 1.17 & 0.93 & 0.80 & 1.07 & 1.10 & 0.75 & 0.80 & 0.90 & 7.52 \\
\hline Sample $2^{2}$ & 1.21 & 0.97 & 0.83 & 1.14 & 1.10 & 0.71 & 0.70 & 0.71 & 7.37 \\
\hline
\end{tabular}

${ }^{1}$ Mousse without ovalbumin.

${ }^{2}$ Mousse with no ovalbumin or citric acid added. 
Table 3. Volume yield of yogurt mousse (medium value for 3 assays)

\begin{tabular}{lll}
\hline & $\begin{array}{l}\text { Mousse } \\
\text { without } \\
\text { ovalbumin }\end{array}$ & $\begin{array}{l}\text { Mousse } \\
\text { with 1.3\% } \\
\text { ovalbumin }\end{array}$ \\
\hline Product & 1.22 & 1.31 \\
Density $(\mathrm{d}=\mathrm{g} / \mathrm{mL})^{1}$ & 0.82 & 0.76 \\
\hline
\end{tabular}

${ }^{1} \mathrm{~d}=$ Density.

it was shown that the incorporation of $1.3 \%$ ovalbumin to the mousse during the process of elaboration hardly alters the properties of the product. Taking into account the production costs of the process, i.e., the cost to produce purified ovalbumin from residual egg white of egg industries using the ion exchange resin and the cost to produce the final mousse with all of the ingredients, the economical benefit increases $\sim 3 \%$ with respect to the product without ovalbumin, as the lower density of the product with ovalbumin compensates the cost to produce the purified ovalbumin. The final product with ovalbumin improves the functional properties, maintaining the rheological and organoleptic characteristics of the product formulated without ovalbumin.

\section{REFERENCES}

Abu-Jdayil, B., and H. Mohameed. 2002. Experimental and modelling studies of the flow properties of concentrated yogurt as affected by the storage time. J. Food Eng. 52:359-365.

Andalzúa, A. 1994. Pages 28-86 in Sensorial Assessment of Foods. Theory and Practise. (In Spanish). Acribia, Zaragoza, Spain.

Awadé, A. C., and T. Efstathiou. 1999. Comparison of 3 liquid chromatographic methods for egg-white protein analysis. J. Chromatogr. B 723:69-74.

Croguennec, T., F. Nau, S. Pezennec, and G. Brule. 2000. Simple rapid procedure of preparation of large quantities of ovalbumin. J. Agric. Food Chem. 48:4883-4889.

Everett, D. W., and N. F. Olson. 2000. Dynamic rheology of renneted milk gels containing fat globules stabilized with different surfactants. J. Dairy Sci. 83:1203-1209.

Galazka, V. B., E. Dickinson, and D. A. Ledward. 2000. Emulsifying properties of ovalbumin in mixtures with sulphated polysaccharides: Effect of $\mathrm{pH}$, ionic strength, heat and high pressure treatment. J. Sci. Food Agric. 80:1219-1229.

Gallegos, C., and J. M. Franco. 1999. Rheology of food, cosmetics and pharmaceuticals. J. Colloid Interface Sci. 4:288-293.
Guerrero, A., P. Partal, and C. Gallegos. 1998. Linear viscoelastic properties of sucrose ester-stabilized oil-in-water emulsions. J. Rheol. 42:1375-1388.

Huntington, J. A., and P. E. Stein. 2001. Structure and properties of ovalbumin. J. Chromatogr. B 756:189-198.

Koh, M. W., L. M. Merino, and E. Dickinson. 2002. Rheology of acidinduced sodium caseinate gels containing added gelatin. Food Hydrocoll. 16:619-623.

Langevin, D. 2000. Influence of interfacial rheology on foam and emulsion properties. Adv. Colloid Interfac. 88:209-222.

Paredes, B., S. González, M. Rendueles, and J. M. Díaz. 2004. Particulate poly(glycidyl methacrylate-co-ethylene dimethacrylate) material for protein separation by anion-exchange chromatography. Sep. Purif. Technol. 40:243-250.

Paredes, B., S. González, M. Rendueles, M. A. Villa-García, and M. Díaz. 2003. Influence of the amination conditions on the textural properties and chromatographic behaviour of amino-functionalized glycidyl methacrylated-based particulate supports. Acta Mater. 51:6189-6198.

Paredes, B., O. Iglesias, and M. Menéndez. 2004. Rheologic study of mousse yogurt. Page 550 in Proc. of Congr. Natl. Biotecnol. BIOTEC'2004. Universidad de Oviedo, Spain.

Paredes, B., E. Suárez, M. Rendueles, M. A. Villa-García, and J. M. Díaz. 2001. Ammonia functionalized particulate poly(glycidyl methacrylate-co-ethylene dimethacrylate)-based polymers as stationary phase for protein retention. J. Chem. Technol. Biotechnol. 76:1171-1178.

Pintado, M. E., J. A. Lopes da Silva, A. I. E. Pintado, and F. X. Malcata. 1998. Rheological characterization under shear of a fraction of polymer produced via fermentation of whey-related media by Rahnella aquatilis. Carbohydr. Polym. 37:1-6.

Rendueles de la Vega, M., C. Chenou, J. M. Loureiro, and A. E. Rodrigues. 1998. Mass transfer mechanism in Hyper D media for chromatographic protein separation. Biochem. Eng. J. 1:11-23.

Schramm, G. 1994. Pages 1-34 in A Practical Approach to Rheology and Rheometry. R. F. A. Haake, ed. Gebrueder HAAKE GmbH, Karlsruhe, Germany.

Shibusana, Y., S. Kihira, and Y. Ito. 1998. One-step purification of proteins from chicken egg white using counter-current chromatography. J. Chromatogr. B 709:301-305.

Stanley, B. J., M. Sarker, and G. Guiochon. 1996. Consolidation of the packing material in chromatographic columns under dynamic axial compression. IV. Mechanical properties of some packing materials. J. Chromatogr. A 741:175-184.

Steffe, J. F. 1996. Rheological Methods in Food Process Engineering. Freeman Press, East Lansing, MI.

Suárez, E., B. Paredes, F. Rubiera, M. Rendueles, M. A. Villa-García, and M. Díaz. 2002. Functionalized, glycidyl methacrylate based polymers as stationary phases for protein retention. Sep. Purif. Technol. 27:1-10.

Vachier, M. C., M. Piot, and A. C. Awadé. 1995. Isolation of hen egg white lysozyme, ovotransferrin and ovoalbumin, using a quaternary ammonium bound to a highly crosslinked agarose matrix. J. Chromatogr B 664:201-210. 